\title{
COMPARATIVE STUDY OF OXIDATIVE TRANSFORMATION OF ALIPHATIC ALCOHOLS BY CE(IV) -ONE ELECTRON KINETICS
}

\section{Chemistry \\ Mamta Baser* Research Scholar, Vikram University, Ujjain, M.P.. *Corresponding Author}

B. K. Dangarh $\quad$ Professor, Department of Chemistry, Govt. P.G. College, Neemuch, M.P..

Y.K.Mishra Professor, Department of Chemistry, Govt. Arts and science College, Ratlam, M.P..

\section{ABSTRACT}

The comparative study of oxidation of aliphatic alcohols likes methanol, ethanol and propanol was carried out by CAN in the presence of perchloric acid in acetonitrile medium. The reaction is first order with respect to [substract], [oxidant] and [ $\mathrm{H}+$ ] concentration. The kinetics of the reaction was followed spectrophotometrically at $\lambda \max =400 \mathrm{~nm}$. The reactions were studied at different temperature [303 to $323 \mathrm{~K}]$. A possible mechanism is proposed here. The reaction constant involved in the mechanism have been computed. There is good agreement between the observed and calculated rate constant under different experimental conditions. The activation parameters have been evaluated.

\section{KEYWORDS}

kinetics, oxidation, aliphatic alcohols, cericammoniumnitrate [CAN].

\section{INTRODUCTION:}

Cericammoniumnitrate $[\mathrm{CAN}]$ is a powerful oxidant that has many uses in oraganic synthesis ${ }^{1}$, Kinetics studies in primary aliphatic alcohols Ce(IV) oxidized into aldehydes in present acetonitrile medium has been investigated by spectrophotometric method ${ }^{2}$. The oxidation of methanol and ethanol by cericammoniumnitrate has been studied spectrophotometrically in the presence of glacial acetic acid in acetonitrile as solvent ${ }^{3}$. Kinetics of cerium(IV) oxidation of aliphatic alcohol ethanol, 1-propanol, 2-propanol,1-butanol and 2-butanol were studied $^{4}$, at $30^{\circ} \mathrm{C}$ in the presence and absence of surfactants in acidic medium. Ethanol can be oxidized to acetaldehyde and acetic acid Secondary alcohols are oxidized to the corresponding kinetics tertiary alcohols ${ }^{6}$. Primary aliphatic alcohol Ce(IV) oxidized into aldehydes in present acetonitrile medium has been investigated by spectrophotometric method ${ }^{7}$. The study of in situ reduction of $\mathrm{Ce}^{4+}$ to $\mathrm{Ce}^{3+}$ a time-resolved $\mathrm{X}$ ray absorption spectroscopy ${ }^{8}$.

\section{METHOD \& MATERIAL:}

Cericammoniumnitrate was prepared by the method of Smith et al. ${ }^{9}$ and its purity was chacked by melting point. All other chemicals used in this investigation were of analytical reagent grade. The Methanol, Ethanol and Propanol were commercial products of the highest purity available. The kinetic runs were followed for good order kinetics was observed.

The rate measurements were carried out at $308 \mathrm{~K}$ in $\mathrm{HClO}_{4}$ under the condition $[$ alcohol] $>>[\mathrm{CAN}]$ in the solvent system of $(\mathrm{V} / \mathrm{V})$. The progress of the reaction was followed by measuring the absorbance of CAN at $400 \mathrm{~nm}$ in one $\mathrm{cm}$ cell Placed in the compartment of systronics VISISCAN-167 spectrophotometer.

\section{RESULTS AND DISCUSSION:}

Oxidation of Methanol, Ethanol \& Propanol by CAN in acetonitrale solvent in presence of perchloric acid under the condition $[\mathrm{CAN}]<<[$ Methanol, Ethanol \& Propanol] had the following kinetics feature.

$\mathrm{CH}_{3} \mathrm{CH}_{2} \mathrm{OH}+2 \mathrm{Ce}(\mathrm{IV}) \longrightarrow \mathrm{CH}_{3} \mathrm{CHO}+2 \mathrm{Ce}(\mathrm{III})+\left[2 \mathrm{H}^{+}\right]$

[Alcohol] [Oxidant] [Aldehyde]

The stoichimetry of the reaction was found to correspond to the equation. The product of oxidation was identified by its 2,4dinitrophenylhydrazine derivative.

\section{(I) Effect of Substrate:-}

The effect of alcohol concentration on the reaction rate was studied at constant $[\mathrm{CAN}],\left[\mathrm{HClO}_{4}\right]$, temperature and acetonitrile. The rate of oxidation increased on increasing the concentration of alcohol. When the logarithms of $\mathrm{k}_{\mathrm{obs}}$ values were plotted against the logarithms of the [alcohol], (figure-1) a linear plot was obtained. The plot of $1 / \mathrm{k}_{\mathrm{obs}}$ versus $1 /[$ alcohol], was found to be straight line with an intercept on the rate ordinate, indicating the oxidation of both the alcohols follow Michaelis-Menten type kinetics and proceeds through the formation of a complex between the oxidant and the substrate

$\mathrm{d}[\mathrm{CAN}] / \mathrm{dt}=\mathrm{k}[$ alcohol $][\mathrm{CAN}] / \mathrm{k}_{\mathrm{M}}+$ alcohol $]$

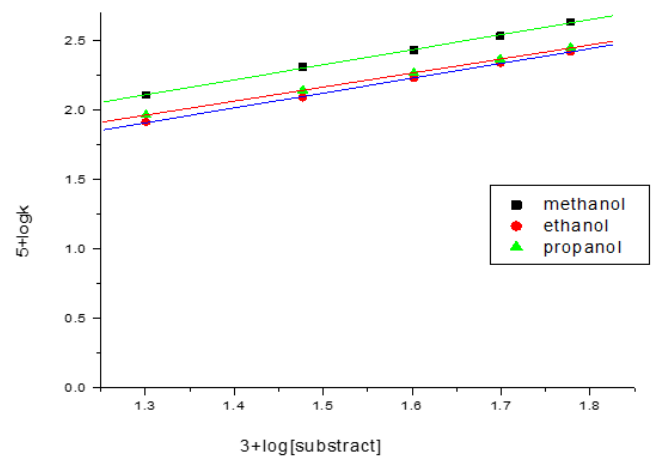

Figure-1 Effect of substrate concentration $\log \mathrm{k}$ v/s $\log$ [substrate]

(ii) Effect Of $\left[\mathrm{H}^{+}\right]$ion:

The effect of hydrogen ion concentration on the rate of the oxidation was studied by varying $\left[\mathrm{H}^{+}\right]$while keeping the concentration of other reagents constant. Since there is no effect of ionic strength on reaction rate therefore ionic strength was not kept constant in this experiment. A steady increase in oxidation rate with increase in the medium suggests the formation of protonated CAN in the rate determining step. The plot of $\log \mathrm{k}_{\mathrm{obs}}$ against $\log \left[\mathrm{H}^{+}\right]$is linear.

\section{(iii) Effect Of Oxidant:}

When alcohols were in excess, the disappearance of CAN followed the first-order rate low constant are independent of the initial concentration of the [CAN] when varied in the range (2 to 7) $\times 10^{-3}$ $\mathrm{mol} / \mathrm{dm}^{-3}$

\section{(iv) Effect Of Solvent Composition:}

Effect of solvent was studied by changing proportion of acetonitrile and water; varied from $50 \%$ acetonitrile $\mathrm{V} / \mathrm{V}$. The reaction rate increased with an increase in the percentage of acetonitrile. Suggesting that a low dielectric medium favors the oxidation (Table-1). A plot of $\log \mathrm{k}$ V/S 1/D (dielectric constant) in liner with a positive slope for the alcohols under study. This indicates an ion-dipole type of interaction in rate-determining step.

Table [1] Effect Of [SUBSTRATE], $\left[\mathrm{H}^{+}\right]$, [SOLVENT], [CAN] = $3 \times 10^{-3} \mathrm{M}, \mathrm{T}=308 \mathrm{~K}$

\begin{tabular}{|c|c|c|c|c|c|}
\hline \multirow[t]{2}{*}{$\begin{array}{l}\text { [Subatrate } \\
\text { ]X10²M }\end{array}$} & \multirow[t]{2}{*}{$\begin{array}{l}{\left[\mathrm{HClO}_{4}\right] \mathrm{X}} \\
10^{2} \mathrm{M}\end{array}$} & \multirow{2}{*}{\begin{tabular}{|l}
$\%$ of $\mathrm{H}_{2} \mathrm{O}$ \\
{$[$ In } \\
Acetonitrile \\
I
\end{tabular}} & $\begin{array}{l}\text { k x 10 } \\
\text { sec-1 }\end{array}$ & $\begin{array}{l}\text { kx10 } \\
\text { sec-1 }\end{array}$ & $\begin{array}{l}\text { kx10 } \\
\text { sec-1 }\end{array}$ \\
\hline & & & \begin{tabular}{|l|} 
Methanol \\
\end{tabular} & Ethanol & Propanol \\
\hline 2 & 0 & $\mathbf{0}$ & \begin{tabular}{|l|}
128.84 \\
\end{tabular} & \begin{tabular}{|l|}
82.43 \\
\end{tabular} & 92.71 \\
\hline 3 & 0 & 0 & 205.49 & 123.85 & 139.29 \\
\hline 4 & 0 & 0 & 271.52 & 170.20 & 185.36 \\
\hline 5 & 0 & 0 & 344.39 & 219.23 & 234.41 \\
\hline 6 & 0 & 0 & 432.66 & 265.98 & 281.87 \\
\hline 2 & 2 & 0 & 128.84 & 82.42 & 92.71 \\
\hline
\end{tabular}




\begin{tabular}{|l|l|l|l|l|l|}
\hline 2 & 2.5 & 0 & 190.60 & 114.27 & 117.91 \\
\hline 2 & 3 & 0 & 240.30 & 151.00 & 141.81 \\
\hline 2 & 3.5 & 0 & 308.82 & 185.38 & 168.98 \\
\hline 2 & 4 & 0 & 377.64 & 219.23 & 194.87 \\
\hline 2 & 4.5 & 0 & 444.57 & 252.76 & 227.44 \\
\hline 2 & 5 & 0 & 517.68 & 294.58 & 248.73 \\
\hline 2 & 2 & 10 & 101.56 & 68.58 & 74.47 \\
\hline 2 & 2 & 20 & 79.82 & 56.61 & 59.82 \\
\hline 2 & 2 & 30 & 59.83 & 47.22 & 47.08 \\
\hline 2 & 2 & 40 & 48.27 & 38.03 & 37.13 \\
\hline 2 & 2 & 50 & 37.49 & 31.35 & 30.60 \\
\hline
\end{tabular}

(v) Effect Of Temperature And Determination Of Activation Parameters:

Rate of oxidation reaction increases with increases in temperature. (Table-2). Rate of reactions were determined at different temperature. In all the cases, a plot of $\log \mathrm{k}_{\text {obs }}$ versus $1 / \mathrm{T}$ (inverse of absolute temperature) is a straight line. This shows that Arrhenius equation is vaid for this oxidation. The energy of activation ranges 54.75, 48.19 and $55.90 \mathrm{~kJ} \mathrm{~mol}^{-1}$. The entropy values are all negative and high value observe. (Table-3).

Table [2] Variation Of Rate With Temprature [SUBSTRATE] = $2.0 \times 10^{-2} \mathrm{M},[$ PERCHLORICACID $]=2 \times 10^{-2} \mathrm{M},[\mathrm{CAN}]=3 \times 10^{-2} \mathrm{M}$

\begin{tabular}{|l|l|l|l|}
\hline TEMPRATURE( K) & Methanol & Ethanol & Propanol \\
\hline $303 \mathrm{k}$ & 128.84 & 82.42 & 92.71 \\
\hline $308 \mathrm{k}$ & 199.07 & 121.31 & 145.50 \\
\hline $313 \mathrm{k}$ & 271.03 & 157.42 & 190.56 \\
\hline $318 \mathrm{k}$ & 379.97 & 215.22 & 268.97 \\
\hline $323 \mathrm{k}$ & 515.82 & 278.77 & 391.28 \\
\hline
\end{tabular}

Table [3] Thermodynamic Parameters:

\begin{tabular}{|c|c|c|c|c|c|}
\hline $\begin{array}{l}\text { [SUBSTRA } \\
\text { TE]X10 } \\
\end{array}$ & $\log A$ & $\begin{array}{l}\text { Energy of } \\
\text { activation } \\
\Delta \mathbf{E}^{\#} \mathbf{k J} \\
\mathbf{m o l}^{-1}\end{array}$ & $\begin{array}{l}\text { Entropy of } \\
\text { activation } \\
\Delta \mathbf{S}^{\#} \mathrm{JK}^{-1} \mathrm{~mol}^{-1}\end{array}$ & $\begin{array}{l}\text { Free } \\
\text { energy of } \\
\text { activation } \\
\Delta \mathbf{G}^{\#} \mathbf{k J} \\
\text { mol- }^{1}\end{array}$ & $\begin{array}{l}\text { Enthalpy } \\
\text { of } \\
\text { activation } \\
\Delta \mathbf{H}^{\#} \mathrm{~kJ} \\
\mathrm{~mol}^{-1} \\
\end{array}$ \\
\hline Methanol & 9.9 & 54.75 & -58.48 & 72.44 & 52.23 \\
\hline Ethanol & 8.62 & 48.19 & -83.84 & 73.59 & 45.67 \\
\hline Propanol & 10.00 & 55.90 & -57.42 & 73.29 & 53.38 \\
\hline
\end{tabular}

\section{CONCLUSION:}

In kinetic study of oxidation of Methanol, Ethanol and Propanol by cericammoniumnitrate (CAN) has found that the reaction was first order with respect to $[\mathrm{CAN}]$ and rate is almost independent of substrate concentration. The reactions are catatyzed by $\left[\mathrm{H}^{+}\right]$. The decreases in dielectric constant increases the rate of reaction. The rate of reaction increases with temperature. Activation parameter were evaluated. A suitable mechanism is proposed involving the hydride ion transfer in rate determining step. The negative values of entropy of activation come under a category of slow reactions.
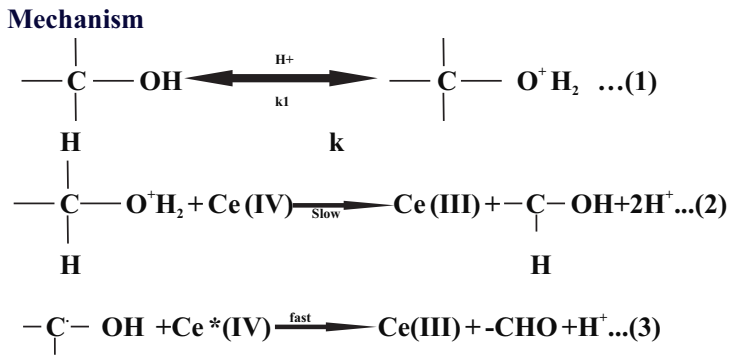

$\mathbf{H}$

\section{Acknowledgement}

We are very thankful to Prof. Dr. B.K.Dangarh for checking and correcting the language. I am thankful to Prof. Dr. Y.K,Mishra for important discussion.

\section{REFERENCES:}

Nair V., Deepthi, A., Chem. Rev.; 107,1862,(2007).

S. S. Kim, H. C. Jung, Synthesis,; 213-2137, (2003).

Dashrath singh rathore, B.K. Dangarh, International journal of scientific research, chemistry,; 6(7), 2277-8178, (2017).

Ghosh aniruddha, saha rumpa, saha, Bidyut, journal of molecular liquids,; 196(8), 223237, (2014).

Briois V., Lutzenkirrchen-Hecht D., Villain F.,Fonda E.,Belin S., Griesebock B., Frahm R., J. Phys. Chem.; 109, 320, (2005). 